\title{
Establishment of mesenchymal stem cell lines derived from the bone marrow of green fluorescent protein-transgenic mice exhibiting a diversity in intracellular transforming growth factor- $\beta$ and bone morphogenetic protein signaling
}

\author{
SHUNSUKE SAWADA ${ }^{1-4^{*}}$, NAOYUKI CHOSA ${ }^{1 *}$, NAOKI TAKIZAWA ${ }^{1,2}$, JUN YOKOTA $^{1,3,5}$, \\ YASUYUKI IGARASHI ${ }^{1,5}$, KOICHI TOMODA ${ }^{4}$, HISATOMO KONDO ${ }^{5}$, \\ TAKASHI YAEGASHI ${ }^{2}$ and AKIRA ISHISAKI ${ }^{1}$
}

\begin{abstract}
${ }^{1}$ Division of Cellular Biosignal Sciences, Department of Biochemistry, Iwate Medical University, Yahaba, Iwate 028-3694;
${ }^{2}$ Division of Periodontology, Department of Conservative Dentistry; ${ }^{3}$ Clinical Research Laboratory, Iwate Medical University School of Dentistry, Morioka, Iwate 020-8505; ${ }^{4}$ Department of Otolaryngology,

Dentistry and Oral Surgery, Kansai Medical University, Hirakata, Osaka 573-1010;

${ }^{5}$ Department of Prosthodontics and Oral Implantology, Iwate Medical University School of Dentistry, Morioka, Iwate 020-8505, Japan
\end{abstract}

Received November 14, 2014; Accepted August 4, 2015

DOI: $10.3892 / \mathrm{mmr} .2016 .4794$

\begin{abstract}
Cytokines and their intercellular signals regulate the multipotency of mesenchymal stem cells (MSCs). The present study established the MSC lines SG-2, -3 , and -5 from the bone marrow of green fluorescent protein (GFP)-transgenic mice. These cell lines clearly expressed mouse MSC markers Sca-1 and CD44, and SG-2 and -5 cells retained the potential for osteogenic and adipogenic differentiation in the absence of members of the transforming growth factor (TGF) $-\beta$ superfamily. By contrast, SG-3 cells only retained adipogenic differentiation potential. Analysis of cytokine and cytokine receptor expression in these SG cell lines showed that bone morphogenetic protein (BMP) receptor 1B was most highly expressed in the SG-3 cells, which underwent osteogenesis in response to BMP, while TGF- $\beta$ receptor II was most highly expressed in SG-3 and -5 cells. However, it was unexpectedly noted that phosphorylation of Smad 2, a major transcription factor, was induced by TGF- $\beta 1$ in SG-2 cells but not in SG-3 or -5 cells. Furthermore, TGF- $\beta 1$ clearly induced the expression of Smad-interacting transcription factor CCAAT/enhancer binding protein- $\beta$ in SG-2 but not in
\end{abstract}

Correspondence to: Dr Shunsuke Sawada, Department of Otolaryngology, Dentistry and Oral Surgery, Kansai Medical University, 2-5-1 Shinmachi, Hirakata, Osaka 573-1010, Japan

E-mail: sawadash@hirakata.kmu.ac.jp

${ }^{*}$ Contributed equally

Key words: green fluorescent protein-transgenic mouse, mesenchymal stem cells, bone morphogenetic protein-2, transforming growth factor- $\beta$, CCAAT/enhancer binding protein- $\beta$
SG-3 or -5 cells. These results demonstrated the establishment of TGF- $\beta$-responsive SG-2 MSCs, BMP-responsive SG-3 MSCs and TGF- $\beta$ /BMP-unresponsive SG-5 MSCs, each of which was able to be traced by GFP fluorescence after transplantation into in vivo experimental models. In conclusion, the present study suggested that these cell lines may be used to explore how the TGF- $\beta$ superfamily affects the proliferation and differentiation status of MSCs in vivo.

\section{Introduction}

Mesenchymal stem cells (MSCs), which were first derived from bone marrow, have self-renewal properties and are able to differentiate into a variety of mesenchymal tissue types (1-3). In stem cell therapy, human bone marrow-derived MSCs (BM-MSCs) are expanded in vitro and subsequently autoimplanted, which eliminates the risk of immune rejection. BM-MSCs are able to differentiate into osteoblasts, chondrocytes and adipocytes (4), and are a major source of bone regeneration and remodeling during homeostasis (5-8). In addition, immunophenotype evaluation demonstrated that mouse BM-MSCs express Sca-1 and CD44, but not CD11b or CD45 (9).

The transforming growth factor (TGF) $-\beta$ superfamily includes the TGF- $\beta$ /activin/Nodal family and the bone morphogenetic protein (BMP)/growth and differentiation factor (GDF)/Mullerian inhibiting substance (MIS) family (10). On the cell surface, binding of ligands to receptors triggers the formation of a tetrameric complex of type I and II receptors. Type II receptor kinase activates type I receptor kinase, which transduces the signal through phosphorylation of receptor-activated Smads (R-Smads) (11-14). Smad proteins are the central mediators of TGF- $\beta$ superfamily signaling. R-Smads, including Smad 1, Smad 5 and Smad 8, are primarily activated by BMP-specific type I receptors, whereas Smad 2 
and Smad 3 are activated by the TGF- $\beta$-specific type I receptors. Activated R-Smads form complexes with the common mediator Smads (Co-Smads; e.g., Smad 4), which translocate into the nucleus, where they and their partner proteins regulate the transcription of specific target genes. Abnormal intensity of Smad-mediated TGF- $\beta /$ BMP signals is associated with various human diseases, including bone and immune disorders, fibrosis, and cancer progression or metastasis (15). Of note, TGF- $\beta$ superfamily-induced intracellular signals affect osteogenesis and adipogenesis of MSCs; for instance, BMP has been observed to potentiate osteogenic and adipogenic differentiation of undifferentiated mesenchymal cells (16). By contrast, TGF- $\beta$ potentiates osteogenic differentiation of BM-MSCs $(17,18)$, although none of these results have been confirmed in vivo.

Recent studies have focused on controlling TGF- $\beta$ /BMP signals for the discovery of pharmacotherapeutics; however, the detection of therapeutic molecular targets in these pathways has not been successful, probably because most trials are performed in vitro, not in vivo $(19,20)$. Therefore, it is important to establish appropriate in vivo experimental models to evaluate the role of TGF- $\beta$ /BMP signaling in disease development or healing. The present study aimed to establish MSC cell lines derived from bone marrow of green fluorescent protein (GFP)-transgenic mice; the cells and their diverse, intracellular BMP and TGF- $\beta$ signals can be tracked after transplantation into in vivo experimental models. These cell lines are available for in vivo molecular studies that aim to determine how the TGF- $\beta$ superfamily affects MSC proliferation and differentiation in diseases including fibrosis and cancer progression or metastasis $(21,22)$, and in tissue repair processes, including tissue reconstruction and anti-inflammatory responses (23).

\section{Materials and methods}

Bone marrow-derived cells from GFP-transgenic mice. All experimental procedures were performed in accordance with the guidelines established by the Animal Studies Committee at Iwate Medical University (Iwate, Japan). A total of four GFP-transgenic mice (24) were obtained from the Center for in vivo Science, Iwate Medical University (Iwate, Japan). The mice were sacrificed by excessive inhalation of $\mathrm{CO}_{2}$. Cells were flushed from the tibia of three-week-old GFP-transgenic mice with phosphate-buffered saline (PBS) containing 0.5\% fetal bovine serum (FBS; PAA Laboratories, GE Healthcare, Piscataway, NJ, USA) and 2 mM EDTA, and then seeded into plastic cell culture dishes (Nunc; Thermo Fisher Scientific, Waltham, MA, USA) with Dulbecco's modified Eagle's medium (DMEM; Sigma-Aldrich, St. Louis, MO, USA) containing $10 \%$ FBS. The cells were cultured for 1 week under hypoxic conditions $\left(5 \% \mathrm{O}_{2}, 5 \% \mathrm{CO}_{2}\right.$ and $\left.90 \% \mathrm{~N}_{2}\right)$. Cells were re-plated upon reaching $80 \%$ confluence.

Co-transfection of hTERT and SV4O large T antigen (SV4OLT) genes. The expanded cells were transfected with pBABE-neo-hTERT and pBABE-pur-SV40LT plasmids encoding neomycin and puromycin resistance (provided by Addgene, Cambridge, MA, USA) with Lipofectamine LTX (Invitrogen Life Technologies, Carlsbad, CA, USA) according to manufacturer instructions. Cells were then incubated in DMEM containing 10\% FBS, $150 \mu \mathrm{g} / \mathrm{ml} \mathrm{G} 418$ (Gibco-BRL, Thermo Fisher Scientific) or $1 \mu \mathrm{g} / \mathrm{ml}$ puromycin (Gibco-BRL) under hypoxic conditions for 12-15 days. The surviving cells were trypsinized and allowed to grow in 90-mm culture dishes.

Single-cell cloning. Single-cell clones were obtained using the limited dilution method. After hTERT and SV40LT transfection and selection with G418 and puromycin, the surviving cells were seeded on a 96-well plate (Nunc) at $0.5 \%$ cells per well, and then cultured under hypoxic conditions. After 10 days, the cells were sub-cultured in 24-well plates (Nunc). This was repeated until confluence was reached at 20 days after single cell cloning. Population doubling (PD) was defined as the number of doublings required for a single cell to reach confluence in a 60-mm culture dish (Nunc) under hypoxic conditions. PD was estimated for clones SG-2, $-3,-5$ and -6 .

Telomeric repeat amplification protocol. Telomerase activity in bone marrow-derived cell lines was assayed by the stretch PCR method using the Quantitative Telomerase Detection kit (Allied Biotech, Vallejo, CA, USA) according to manufacturer's instructions. The PCR mixture contained QTD premixed buffer and SYBR green one dye (cat. no. MT3010; Allied Biotech, Inc., St. Benicia, CA, USA). Quantification of telomerase activity was performed under the following amplification conditions using a Thermal Cycler Dice Real Time system (Takara Bio, Otsu, Japan) according to manufacturer's instructions: $25^{\circ} \mathrm{C}$ for $20 \mathrm{~min}$, initial activation at $95^{\circ} \mathrm{C}$ for $10 \mathrm{~min}$, denaturation at $90^{\circ} \mathrm{C}$ for $30 \mathrm{~s}$, annealing at $60^{\circ} \mathrm{C}$ for $30 \mathrm{~s}$, and a final extension of 40 cycles at $72^{\circ} \mathrm{C}$ for $30 \mathrm{~s}$. The PCR products were separated by $10-20 \%$ polyacrylamide gel electrophoresis and stained with ethidium bromide.

Detection of SV4OLT by immunocytochemistry. Bone marrow-derived cell lines were seeded onto eight-well culture slides (BD Biosciences, Franklin Lakes, NJ, USA). After $24 \mathrm{~h}$, the cells were fixed with $4 \%$ paraformaldehyde and washed five times with PBS. For detection of SV40LT, cells were incubated with mouse monoclonal anti-SV40LT (1:100; cat. no. ab16879; Abcam, Cambridge, UK) antibody for $1 \mathrm{~h}$ at room temperature. The cells were then incubated with Alexa Fluor 594 goat polyclonal anti-mouse secondary antibodies (1:500; cat. no. A11005; Thermo Fisher Scientific) and DAPI (1:500; cat. no. D9542; Sigma-Aldrich) for 30 min at room temperature. Fluorescence was examined by using a fluorescence microscope (Olympus ix70; Olympus Corporation, Tokyo, Japan).

Detection of MSC markers by flow cytometry. A total of $1.0 \times 10^{5}$ bone marrow-derived cell lines (SG-2, $-3,-5$ and -6) were suspended in PBS containing 0.5 FBS and 2 mM EDTA and incubated with phycoerythrin-conjugated monoclonal anti-mouse Sca-1 (1:10; cat. no. 130-093-224), monoclonal anti-mouse CD44 (1:10; cat. no. 130-096-838), monoclonal anti-mouse CD11b (1:10; cat. no. 130-091-240) or monoclonal anti-mouse CD45 (1:10; cat. no. 130-091-610) antibody for $1 \mathrm{~h}$ at $4^{\circ} \mathrm{C}$ in the dark. All antibodies were purchased from Miltenyi Biotec (Bergisch Gladbach, Germany). Acquisition was performed using an EPICS XL ADC system (Beckman Coulter, Brea, CA, USA). 


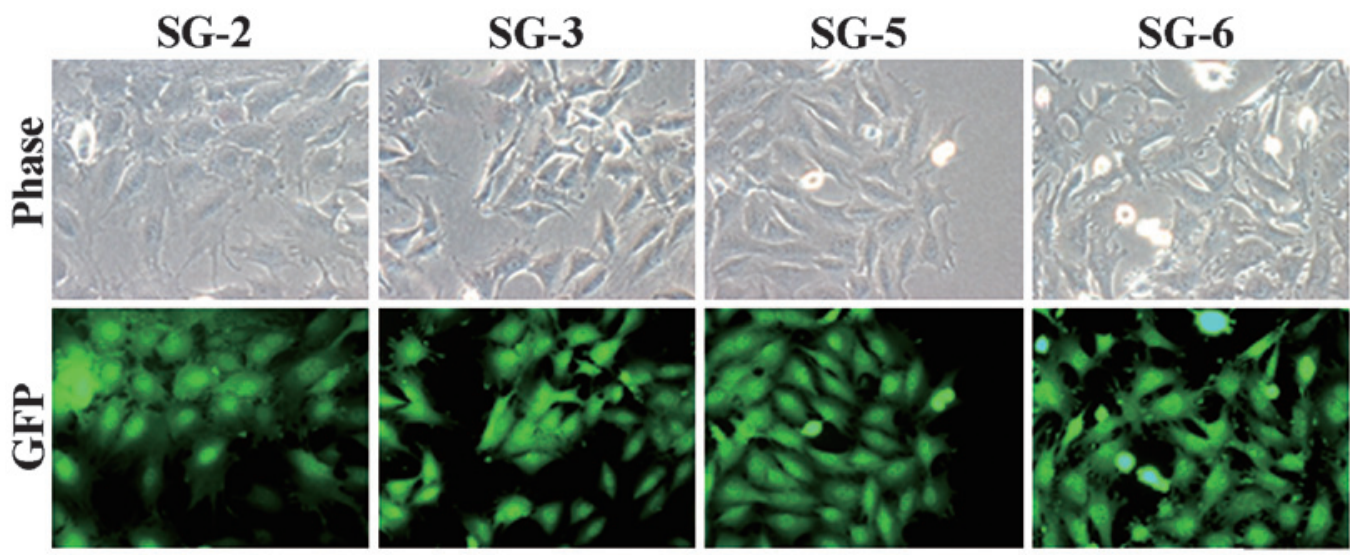

Figure 1. SG-2, -3, -5, and -6 cell lines derived from the bone marrow of tibia from GFP-transgenic mice imaged by phase-contrast (upper panel) and fluorescence (blue filter; lower panel) microscopy. GFP, green fluorescence protein.

Adipogenic and osteogenic differentiation. In vitro differentiation was performed according to a previous study by our group (25). To induce osteogenic differentiation, confluent cells were incubated in osteogenic differentiation medium (ODM) under hypoxic conditions for two weeks. Bone matrix mineralization was evaluated by Alizarin red S (Sigma-Aldrich) staining. To induce adipogenic differentiation, cells were cultured to near confluence and cultured in adipogenic differentiation medium (ADM) under hypoxic conditions for two weeks. At the end of the differentiation period, lipid droplets were stained with Oil Red O (Sigma-Aldrich).

Expression profiling of cytokines and cytokine receptors. Gene expression profiling was performed using a PrimerArray of mouse cytokine-cytokine receptor interaction (Takara Bio) in combination with a Thermal Cycler Dice Real Time System (Takara Bio) according to manufacturer's instructions. This PrimerArray is a set of real-time reverse transcription-polymerase chain reaction (RT-PCR) primers used for the analysis of RNA expression. The array contains a mixture of 96 primer pairs for 88 target genes and eight housekeeping genes. Quantification of gene expression was performed using a PrimerArray Analysis Tool version 2.0 (Takara Bio).

Western blot analysis. SG-2,-3 and -5 cells were serum-starved overnight and stimulated with $50 \mathrm{ng} / \mathrm{ml}$ BMP-2 (R\&D Systems, Minneapolis, MN, USA) or $50 \mathrm{ng} / \mathrm{ml} \mathrm{TGF-} \beta 1$ (R\&D Systems). The cells were washed twice with ice-cold PBS and then lysed in radioimmunoprecipitation assay buffer (50 mM Tris- $\mathrm{HCl}, \mathrm{pH} 7.2,150 \mathrm{mM} \mathrm{NaCl}, 1 \% \mathrm{NP}-40,0.5 \%$ sodium deoxycholate, and $0.1 \%$ SDS) containing protease and phosphatase inhibitor cocktails (Sigma-Aldrich). The protein content was quantified using the bicinchoninic acid method (Pierce; Thermo Fisher Scientific). Samples containing equal amounts of protein were separated by $12.5 \%$ SDS-PAGE and transferred onto a polyvinylidene difluoride membrane (Merck Millipore, Darmstadt, Germany). After blocking with $5 \%$ nonfat dry milk in $50 \mathrm{mM}$ Tris- $\mathrm{HCl}, \mathrm{pH} 7.2$, containing $150 \mathrm{mM} \mathrm{NaCl}$ and $0.1 \%$ Tween-20 for $2 \mathrm{~h}$ at room temperature, the membrane was incubated with primary rabbit monoclonal anti-phospho-Smad 5 (1:1,000; cat. no. ab92698; Abcam), anti-Smad 1/5/8 (1:1,000, cat. no. 12656; Cell
Signaling Technology, Danvers, MA, USA), rabbit monoclonal anti-phospho-Smad 2 (1:1,000; cat. no. 04-953; Merck Millipore), or anti-Smad 2/3 (1:1,000; cat. no. 610843; BD Biosciences) antibody overnight at $4{ }^{\circ} \mathrm{C}$, with mouse monoclonal anti- $\beta$-actin (1:1,000; cat. no. sc-47778; Santa Cruz Biotechnology, Dallas, TX, USA) antibody as a loading control. The blots were incubated with alkaline phosphatase-conjugated secondary antibody and developed using the 5-bromo-4-chloro-3'-indolyphosphate/nitro-blue tetrazolium membrane phosphatase substrate system (cat. no. 50-81-00; Kirkegaard \& Perry Laboratories, Gaithersburg, MD, USA).

RNA isolation and RT-quantitative (q)PCR. SG-2, -3 and -5 cells were stimulated with TGF- $\beta 1$ (1-50 ng/ml; R\&D Systems) for $24 \mathrm{~h}$. Total RNA was isolated using ISOGEN reagent (Nippongene, Tokyo, Japan) according to the manufacturer's instructions. First-strand cDNA was synthesized from total RNA with the PrimeScript RT Reagent kit (Takara Bio). RT-qPCR was performed on a Thermal Cycler Dice Real Time System (Takara Bio) with SYBR Premix Ex Taq II (Takara Bio). Expression of CCAAT/enhancer binding protein- $\beta(\mathrm{C} / \mathrm{EBP} \beta)$ was normalized to $\beta$-actin and relative expression levels were calculated as a fold-increase or -decrease relative to the control. Transcripts were detected with primers (designed using a Perfect Real Time Support system; Takara Bio) for C/EBP $\beta$ (sense, 5'-GACAAGCTGAGCGAC GAGTA-3'; and anti-sense, 5'-AGCTGCTCCACCTTCTTC TG-3') and $\beta$-actin (sense, 5'-CATCCGTAAAGACCTCTA TGCCAAC-3' and anti-sense, 5'-ATGGAGCCACCGATC CACA-3'). For each PCR run, cDNA derived from 50 ng total RNA was used. Following initial denaturation at $95^{\circ} \mathrm{C}$ for $30 \mathrm{~s}$, a two-step cycle procedure was used (denaturation at $95^{\circ} \mathrm{C}$ for $5 \mathrm{~s}$ and annealing and extension at $60^{\circ} \mathrm{C}$ for $30 \mathrm{~s}$ ) for 40 cycles. The relative mRNA expression levels in each sample were calculated using the $2^{-\Delta \Delta \mathrm{CT}}$ method (26).

Statistical analysis. All experiments were repeated at least three times. Representative images or data are shown. Values are expressed as the mean \pm standard deviation. Differences between control and test samples were analyzed using paired two-tailed Student's t-tests. $\mathrm{P}<0.05$ was considered to indicate a statistically significant difference between values. 
A
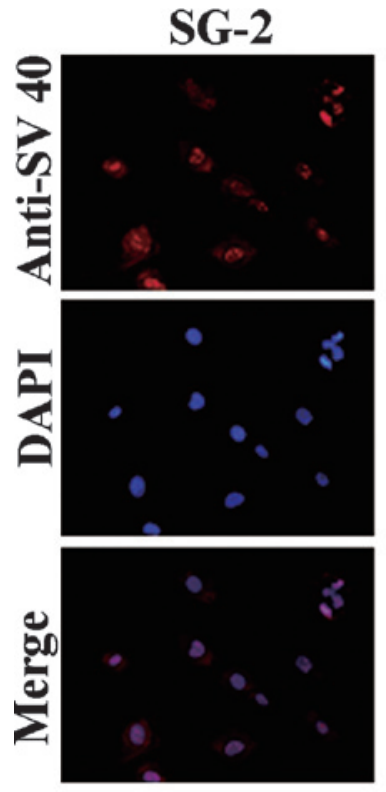
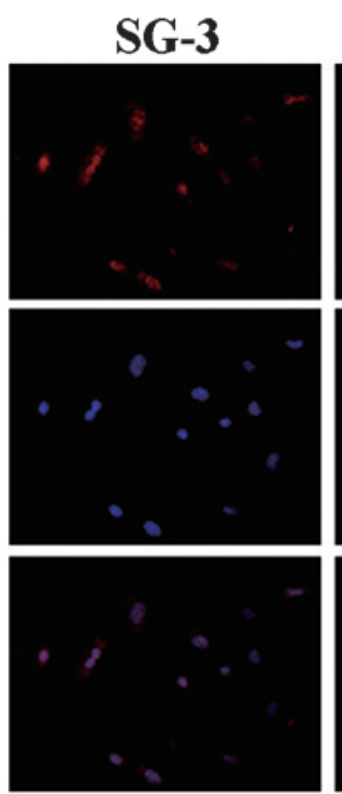
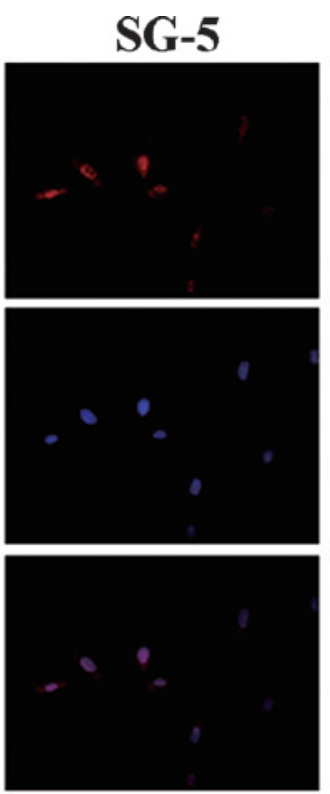
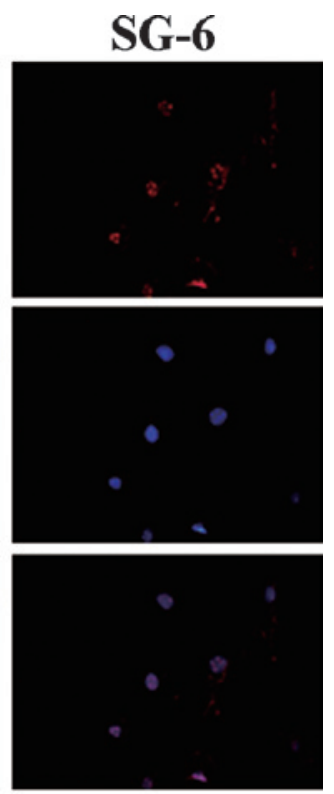

B

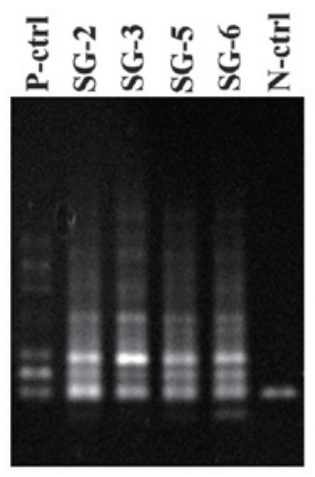

C

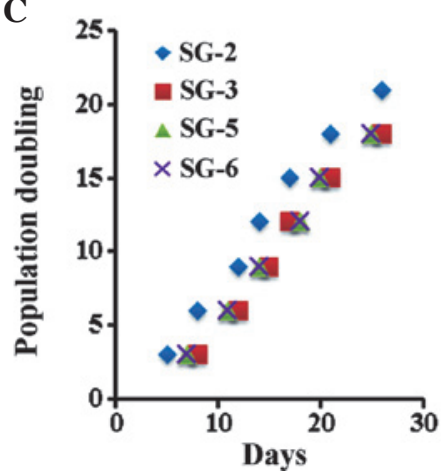

Figure 2. Immortalizing gene expression in SG-2, -3, -5, and -6 cells. (A) SV40 large T antigen immunofluorescence imaging with Alexa Fluor 594 and DAPI (nuclei). (B) Telomerase activity assessed by stretch polymerase chain reaction assay using $10-20 \%$ polyacrylamide gels and visualization with ethidium bromide, and are representative of three independent experiments. (C) Population doubling under hypoxic conditions. Population doubling and the incubation day were considered zero when single-cell cloning was performed. $\mathrm{P} / \mathrm{N}$-ctrl, positive/negative control.

\section{Results}

Establishment of cell lines from the bone marrow of GFP-transgenic mice. Bone marrow cells were flushed from the tibia of GFP mice and cultured under hypoxic conditions. Adherent cells were transformed with hTERT and SV40LT vectors, yielding four single cell-derived cell lines SG-2, $-3,-5$ and -6. As shown in Fig. 1, the cell lines exhibited fibroblastic morphology (Fig. 1, upper panel) and GFP fluorescence (Fig. 1, lower panel). All cell lines exhibited nuclear SV40LT expression (Fig. 2A). At PD 20, a stretch PCR assay indicated telomerase activity in all cell lines, but not in the negative control (Fig. 2B). Thus, the bone marrow-derived cell lines exhibited telomerase activity and SV40LT expression. All cell lines grew at a similar rate of $\sim 1$ PD every two days (Fig. 2C). The cells divided at least 60 times and were passaged $>30$ times, thus demonstrating successful immortalization.

Bone marrow-derived SG cell lines have MSC-like features. To determine their MSC character, the SG-2, $-3,5$, and -6 cell lines were analyzed for the expression of mouse MSC markers and differentiation potential. Sca-1 is the most reliable MSC marker in mice and was strongly expressed in SG-2, -3 and -5 cells, but only weakly expressed in SG-6 cells (Fig. 3). CD44 was detected at similar levels in all cell lines, although the hematopoietic stem cell markers CD11b and CD45 were not detected. The expression patterns of MSC markers suggested that the SG-2, -3 and -5 cell lines were MSCs. Next, the present study evaluated the osteogenic and adipogenic differentiation potentials of these cell lines. Bone matrix mineralization indicated by Alizarin red staining was highest in SG-5 cells (Fig. 4A). Although mineralization was observed in SG-2 cells, it was markedly lower than that in SG-5 and was not detected in SG-3 and SG-6 cells. Thus, SG-2 and -5 cells retained their osteogenic differentiation potential, although at different levels of efficiency. Lipid droplet formation indicated by Oil Red O staining was more intense in SG-2 cells than in SG-3 and -5 cells (Fig. 4B). Thus, SG-2, -3 , and -5 retained their adipogenic differentiation potential to various degrees.

Intercellular signaling by TGF- $\beta$ and BMP in $S G$ cells. In order to identify the expression profiles of cytokines and cytokine receptors in SG cells, the present study performed PrimerArray analyses and compared the results derived from SG-2, -3 and -5 


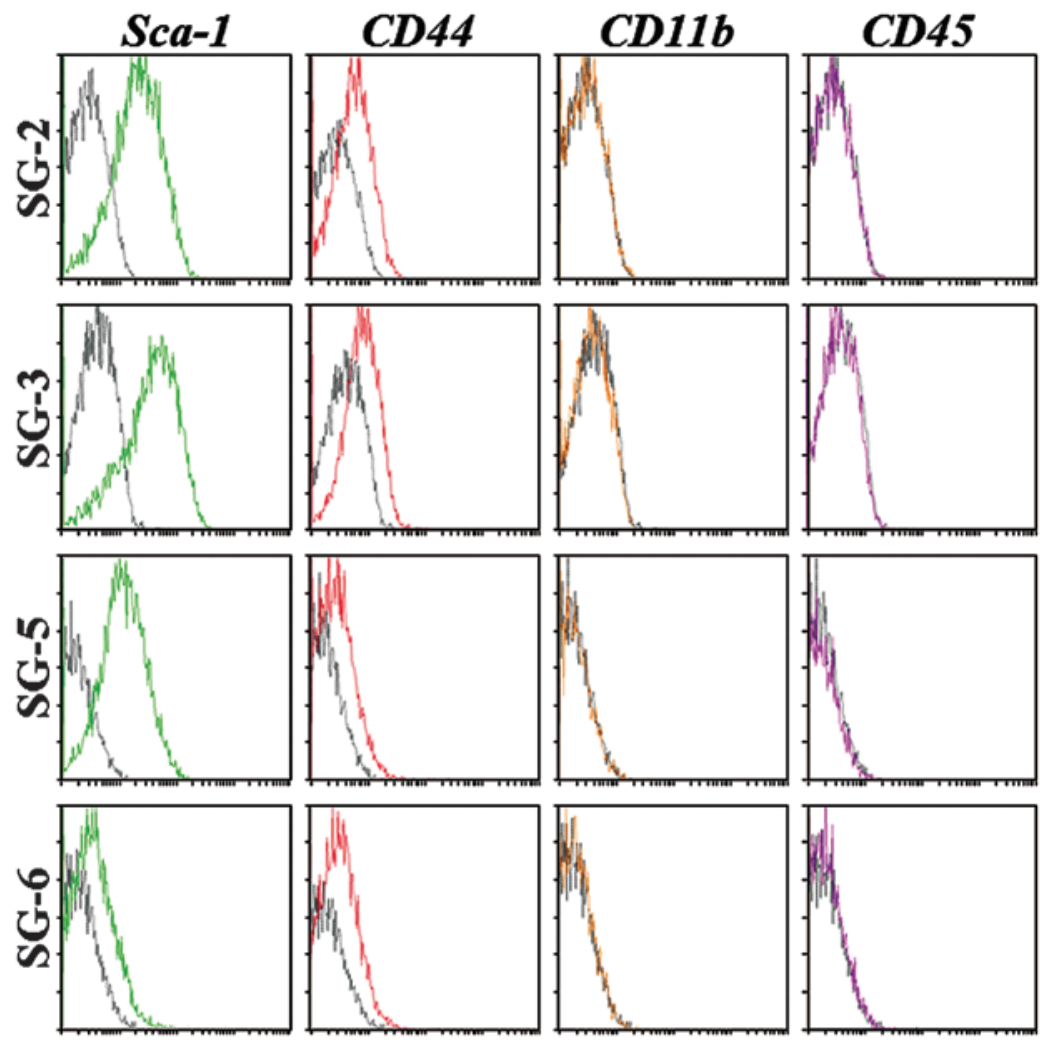

Figure 3. Identification of mouse mesenchymal stem cell markers in SG-2, $-3,-5$, and -6 cell by flow cytometry. The cell lines were incubated with phycoerythrin-conjugated control immunoglobulin G (black), anti-Sca-1 (green), anti-CD44 (red), anti-CD1lb (yellow), or anti-CD45 (purple) antibody and acquisition was performed on a EPICS XL ADC system.

A

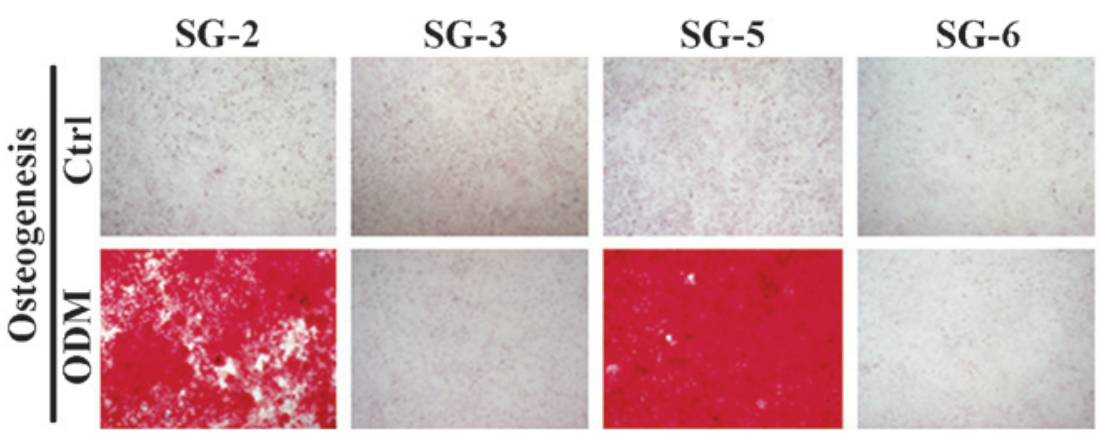

B

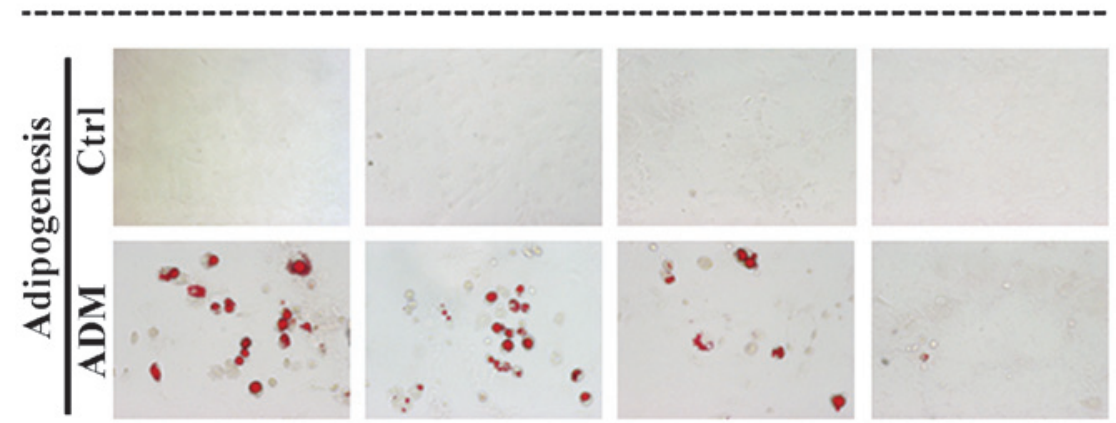

Figure 4. Differentiation potential of SG-2, $-3,-5$, and -6. The cell lines were cultured in (A) ODM or (B) ADM. After 2 weeks, the cells were evaluated for (A) extracellular matrix mineralization by alizarin red staining and (B) for adipogenic differentiation by Oil-Red O staining. Ctrl, control; ODM, osteogenic differentiation medium; ADM, adipogenic differentiation medium.

cells. Differentially expressed genes are shown in Table I. BMP receptor 1B (Bmprlb) was most highly expressed in SG-3 cells, while TGF- $\beta$ receptor II (Tgfbr2) was most highly expressed in SG-3 and -5 cells, indicating differential sensitivities to BMP-2 and TGF- $\beta$. Smad 5, which is a major signaling factor activated by BMP, was most significantly phosphorylated in 
Table I. Genes for which expression changed by >2-fold in SG-2 vs. SG-3 and SG-5.

Fold change with SG-2

\begin{tabular}{|c|c|c|c|}
\hline \multirow{2}{*}{ Gene symbol } & \multirow[b]{2}{*}{ Gene name } & \\
\hline & & vs. SG-3 & vs. SG-5 \\
\hline Bmprlb & Bone morphogenetic protein receptor, type $1 \mathrm{~B}$ & 45.89 & -2.362 \\
\hline Egfr & Epidermal growth factor receptor & 4.228 & 6.453 \\
\hline Ifngr 2 & Interferon $\gamma$ receptor 2 & 1.181 & -3.534 \\
\hline Il17ra & Interleukin 17 receptor A & 2.266 & 1.790 \\
\hline Ill $18 r 1$ & Interleukin 18 receptor 1 & 3.811 & 1.007 \\
\hline Pdgfrb & Platelet derived growth factor receptor, beta polypeptide & 2.514 & 1.625 \\
\hline Cx3cll & Chemokine (C-X3-C motif) ligand 1 & 5.315 & 2.346 \\
\hline Tgfbrl & Transforming growth factor, beta receptor I & 2.056 & 1.778 \\
\hline$T g f b r 2$ & Transforming growth factor, beta receptor II & 2320 & 2702 \\
\hline$H g f$ & Hepatocyte growth factor & 14.83 & 5.098 \\
\hline$K d r$ & Kinase insert domain protein receptor & 8.574 & 2.888 \\
\hline Lepr & Leptin receptor & 2.144 & 1.495 \\
\hline$P d g f b$ & Platelet-derived growth factor, B polypeptide & 4.823 & 4.993 \\
\hline Pdgfra & Platelet-derived growth factor receptor, alpha polypeptide & 2.329 & 1.444 \\
\hline Prlr & Prolactin receptor & -2.071 & -1.014 \\
\hline Ccl9 & Chemokine ( $\mathrm{C}-\mathrm{C}$ motif) ligand 9 & -2.174 & 1.050 \\
\hline Tnfrsflb & Tumor necrosis factor receptor superfamily, member $1 \mathrm{~b}$ & 2.129 & 1.879 \\
\hline$C d 40$ & CD40 antigen & -1.319 & -27.48 \\
\hline$I l 2 r g$ & Interleukin 2 receptor, $\gamma$ chain & 7.160 & 2.789 \\
\hline Lifr & Leukemia inhibitory factor receptor & 1.602 & 4.112 \\
\hline Kitl & Kit ligand & 2.000 & 1.283 \\
\hline Cntfr & Ciliary neurotrophic factor receptor & 5.938 & 5.242 \\
\hline Cxcl14 & Chemokine (C-X-C motif) ligand 14 & 7.835 & 5.205 \\
\hline$I l 17 r b$ & Interleukin 17 receptor B & -2.250 & 3.074 \\
\hline Ccl8 & Chemokine (C-C motif) ligand 8 & 1.919 & 2.346 \\
\hline
\end{tabular}

BMP 2-stimulated SG-3 cells (Fig. 5A). In addition, osteogenic differentiation in SG-3 cells was induced by stimulation with BMP-2 in a dose-dependent manner (Fig. 5B), suggesting these cells retained the capacity to differentiate into adipogenic (Fig. 4B) and osteogenic lineages. However, phosphorylation of Smad 2, which is activated by TGF- $\beta$, was highest in the MSC-like SG-2 cells in response to TGF- $\beta 1$ (Fig. 6A). Of note, mRNA expression of $\mathrm{C} / \mathrm{EBP} \beta$, which is an immune- and inflammatory response-associated as well as Smad-interacting transcription factor, was induced in SG- 2 cells by TGF- $\beta 1$ in a dose-dependent manner (Fig. 6B). Thus, the SG-3 cells were BMP-responsive and the SG-2 cells were TGF- $\beta$-responsive, while SG-5 cells were BMP/TGF- $\beta$-unresponsive MSCs.

\section{Discussion}

In the present study, the bone marrow of GFP mice was used to establish three MSC lines immortalized by transfection with SV40LT and hTERT. SV40LT-transformed cells are not tumorigenic (27-30); therefore, SV40LT is commonly used to immortalize primary mammalian cells. Another commonly used gene for immortalization is TERT, which maintains telomere length to enable cells to indefinitely proliferate. TERT expression is high in stem cells, while it is reduced upon differentiation. Restoration of TERT activity in normal somatic cells can lead to their immortalization and may be associated with the acquisition of characteristics associated with cellular transformation (31). It has been indicated that ectopic expression of the mouse TERT catalytic sub-unit does not affect embryonic stem cell proliferation or differentiation in vitro, but protects them from cell death during differentiation (32). Therefore, the cell lines generated in the present study may be used to study stem cell proliferation and differentiation.

The expression of MSC markers Sca- $1^{+}$and $\mathrm{CD}_{4} 4^{+}$and the absence of hematopoietic stem cell markers $\mathrm{CD}_{11} \mathrm{~b}^{-}$and CD45- were confirmed in SG-2, -3 and -5 cells, which exhibited osteogenic and adipogenic differentiation potential. These results strongly suggested that the MSC-like potential of the cells was preserved. The present study focused on cytokines and cytokine receptors that are expressed specifically in each cell line to clarify the differentiation mechanism of MSCs: Bmprlb was most highly expressed in SG-3 but not in SG-2 or -5 cells, whereas $T g f b r 2$ was most highly expressed in SG-3 and -5 but not in SG-2 cells. BMP-2 induced phosphorylation of Smad 5 in SG-3 but not in SG-2 and -5 cells. Furthermore, BMP-2 induced osteogenic differentiation of SG-3 cells but did not affect osteogenic differentiation in SG-2 and -5 cells (data not shown). By contrast, TGF- $\beta$ unexpectedly but clearly induced Smad 2 
A

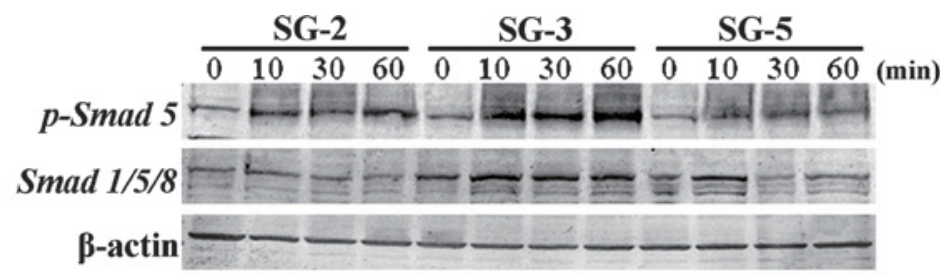

B BMP-2 (ng/ml)

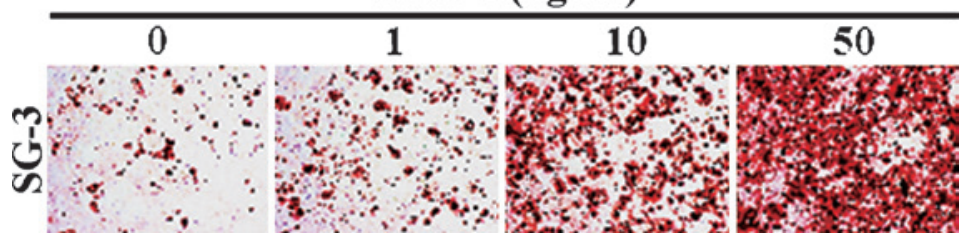

Figure 5. Osteogenic differentiation of SG-3 cells was induced by BMP-2. (A) Phosphorylation status was analyzed by western blotting, and the blots are representative of three independent experiments. (B) After 2 weeks of culture in osteogenic differentiation medium containing BMP-2, bone matrix mineralization was evaluated by Alizarin red S staining. BMP, bone morphogenetic protein.

A
\begin{tabular}{lrrr}
\multicolumn{4}{c}{ SG-2 } \\
\hline 0 & 10 & 30 & 60
\end{tabular}

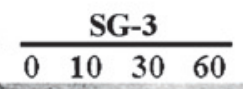

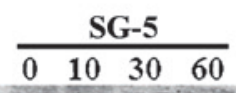

p-Smad 2

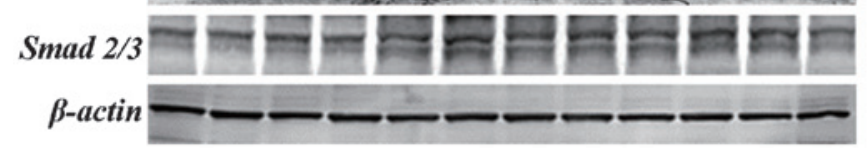

B

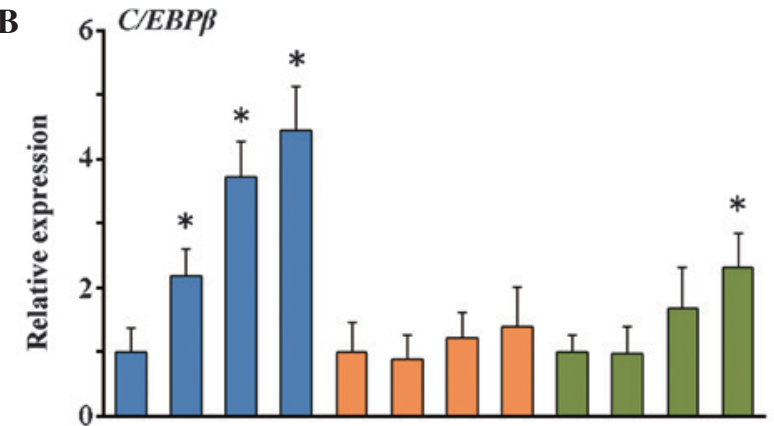

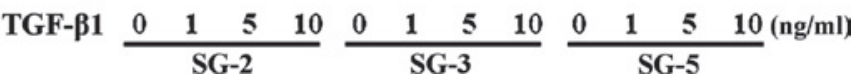

Figure 6. Expression of C/EBP $\beta$ induced by TGF- $\beta$ in SG-2 cells. (A) The phosphorylation status was analyzed by western blotting, and the blots are representative of three independent experiments. (B) Transcript expression of C/EBP $\beta$ was assessed after $24 \mathrm{~h}$, normalized to $\beta$-actin and expressed as a fold-increase or -decrease relative to the control $(0 \mathrm{ng} / \mathrm{ml} \mathrm{TGF}-\beta)$. Values are expressed as the mean \pm standard deviation. " $\mathrm{P}<0.05$ vs. untreated group. $\mathrm{C} / \mathrm{EBP} \beta$, CCAAT/enhancer binding protein- $\beta$; TGF, transforming growth factor; $p$, phosphorylated.

phosphorylation in SG-2 cells, in which expression of TGF- $\beta$ receptors I and II was lower than in SG-3 and -5 cells, suggesting that Smad 2 itself or signal transduction molecules upstream of Smad 2 may have been inactivated in SG-3 and -5 cells. Thus, the present study established TGF- $\beta$-responsive SG-2 cells, BMP-responsive SG-3 cells and TGF- $\beta$ /BMP-unresponsive SG-5 cells that can be traced by GFP fluorescence after transplantation into in vivo experimental models.

Of note, TGF- $\beta$ stimulation of SG-2 induced expression of C/EBP $\beta$, a Smad-interacting transcription factor (33). $\mathrm{C} / \mathrm{EBP} \beta$ is a member of the C/EBP family of transcription factors $(\mathrm{C} / \mathrm{EBP} \alpha, \mathrm{C} / \mathrm{EBP} \beta, \mathrm{C} / \mathrm{EBP} \gamma, \mathrm{C} / \mathrm{EBP}, \mathrm{C} / \mathrm{EBP} \varepsilon$ and $\mathrm{C} / \mathrm{EBP} \xi)$ (34-36). $\mathrm{C} / \mathrm{EBP} \beta$ was first described in 1990 as a basic leucine zipper-structured factor that binds to the interleukin (IL)-1-responsive element in the IL-6 promoter (37). $\mathrm{C} / \mathrm{EBP} \beta$ is highly expressed in myelomonocytic cells and macrophages (38-41). Extracellular signals, including differentiation- or proliferation-inducing agents, hormones, cytokines and inflammatory substances, as well as bacterial and other microbial products can activate or inhibit $\mathrm{C} / \mathrm{EBP} \beta$ via distinct signal transduction pathways. The expression and/or activation of $\mathrm{C} / \mathrm{EBP} \beta$ is regulated by transcriptional mechanisms, mammalian target of rapamycin (mTOR)-mediated alternative translation, post-translational modifications and protein-protein interactions $(35,42,43)$. Upon its activation, C/EBP $\beta$ induces or represses a variety of genes, including cytokines, chemokines and their receptors, other pro-inflammatory genes and pro-proliferative or differentiation-associated markers, as well as metabolic enzymes (34). $\mathrm{C} / \mathrm{EBP} \beta$ thereby affects associated cellular functions, including proliferation $(40,42)$, differentiation $(39,41,44)$, metabolic regulation $(45,46)$ and orchestration of the immune response (47-49). Furthermore, C/EBP $\beta$ is implicated in the pathogenesis of various common diseases, including cancer, hyper-/hypo-inflammation and bacterial/viral infections $(34,50)$. Expression and activation of C/EBP $\beta$ induces the production of monocyte chemotactic protein-1 (MCP-1) (51-54), a member of the $\mathrm{C}-\mathrm{C}$ motif chemokine ligand-2, which induces leukocyte migration to inflamed tissues and organs $(55,56)$. In addition, MCP-1 is secreted by primary breast tumors and stimulates migration of MSCs to tumor lesions (57). MCP-1, stromal cell-derived factor-1, macrophage inflammatory protein- $1 \alpha$ and monocyte chemotactic protein-3 are the most widely reported MSC homing factors (58-61). Stem cell therapy relies on the appropriate homing and engraftment capacity of stem cells (62). Therefore, SG-2 can be used for in vivo studies of TGF- $\beta$-dependent anti-inflammation and stem cell homing. 
Abnormal intensity of Smad-mediated TGF- $\beta$ /BMP signals in MSCs is associated with various human diseases, including bone and immune disorders, fibrosis, and cancer progression or metastasis. However, the detection of therapeutic molecular targets for these diseases in the TGF- $\beta$ /BMP signaling pathways has not been successful as most studies have been performed in vitro. The present study established MSC lines, including TGF- $\beta$-responsive SG-2, BMP-responsive SG-3, and TGF- $\beta$ /BMP-unresponsive SG- 5 cells, which can be traced by GFP fluorescence after transplantation into in vivo experimental models. These cell lines can be used to explore how TGF- $\beta$ /BMP-induced Smad-mediated signals affect proliferation and differentiation of MSCs in vivo, providing insight into various human diseases, including bone and immune disorders, fibrosis and cancer progression or metastasis.

\section{Acknowledgements}

The present study was supported in part by KAKENHI grants-in-aid from the Japan Society for the Promotion of Science (grant nos. 25893221 to S.S., 25463053 to N.C., 26893248 to J.Y., 26462932 to H.K. and 26670852 to A.I.), a grant-in-aid for Strategic Medical Science Research Centre from the Ministry of Education, Culture, Sports, Science and Technology of Japan (2010-2014), a grant from the Keiryokai Research Foundation (no. 120 to S.S., 2013) and the Fund of Academic Society for Research in Otolaryngology (Kansai Medical University, Hirakata, Japan).

\section{References}

1. Prockop DJ: Marrow stromal cells as stem cells for nonhematopoietic tissues. Science 276: 71-74, 1997.

2. Pittenger MF, Mackay AM, Beck SC, Jaiswal RK, Douglas R, Mosca JD, Moorman MA, Simonetti DW, Craig S and Marshak DR: Multilineage potential of adult human mesenchymal stem cells. Science 284: 143-147, 1999.

3. Docheva D, Popov C, Mutschler W and Schieker M: Human mesenchymal stem cells in contact with their environment: Surface characteristics and the integrin system. J Cell Mol Med 11: 21-38, 2007.

4. Baksh D, Song L and Tuan RS: Adult mesenchymal stem cells: Characterization, differentiation and application in cell and gene therapy. J Cell Mol Med 8: 301-316, 2004.

5. Kassem M, Abdallah BM and Saeed H: Osteoblastic cells: Differentiation and trans-differentiation. Arch Biochem Biophys 473: 183-187, 2008.

6. Jones E and Yang X: Mesenchymal stem cells and bone regeneration: Current status. Injury 42: 562-568, 2011.

7. Proff P and Römer P: The molecular mechanism behind bone remodelling: A review. Clin Oral Investig 13: 355-362, 2009.

8. Lazar-Karsten P, Dorn I, Meyer G, Lindner U, Driller B and Schlenke P: The influence of extracellular matrix proteins and mesenchymal stem cells on erythropoietic cell maturation. Vox Sang 101: 65-76, 2011.

9. Yew TL, Chang MC, Hsu YT, Weng WH, Tsai CC, Chiu FY, Hung SC and He FY: Efficient expansion of mesenchymal stem cells from mouse bone marrow under hypoxic conditions. J Tissue Eng Regen Med 7: 984-993, 2013.

10. Weiss A and Attisano L: The TGF beta superfamily signaling pathway. Wiley Interdiscip Rev Dev Biol 2: 47-63, 2013.

11. Miyazawa K, Shinozaki M, Hara T, Furuya T and Miyazono K: Two major Smad pathways in TGF-beta superfamily signalling. Genes Cells 7: 1191-1204, 2002

12. Heldin CH, Landström M and Moustakas A: Mechanism of TGF-beta signaling to growth arrest, apoptosis and epithelial-mesenchymal transition. Curr Opin Cell Biol 21: 166-176, 2009.

13. Meulmeester E and Ten Dijke P: The dynamic roles of TGF- $\beta$ in cancer. J Pathol 223: 205-218, 2011
14. Imamura T, Oshima Y and Hikita A: Regulation of TGF- $\beta$ family signaling by ubiquitination and de ubiquitination. J Biochem 154: 481-489, 2013.

15. Herhaus L and Sapkota GP: The emerging roles of deubiquitylating enzymes (DUBs) in the TGF $\beta$ and BMP pathways. Cell Signal 26: 2186-2192, 2014.

16. Lee SY, Lee JH, Kim JY, Bae YC, Suh KT and Jung JS: BMP2 increases adipogenic differentiation in the presence of dexamethasone, which is inhibited by the treatment of TNF- $\alpha$ in human adipose tissue-derived stromal cells. Cell Physiol Biochem 34: 1339-1350, 2014.

17. Pountos I, Georgouli T, Henshaw K, Bird H, Jones E and Giannoudis PV: The effect of bone morphogenetic protein-2, bone morphogenetic protein-7, parathyroid hormone and platelet-derived growth factor on the proliferation and osteogenic differentiation of mesenchymal stem cells derived from osteoporotic bone. J Orthop Trauma 24: 552-556, 2010.

18. Yokota J, Chosa N, Sawada S, Okubo N, Takahashi N, Hasegawa T, Kondo $\mathrm{H}$ and Ishisaki A: PDGF-induced PI3K-mediated signal enhances TGF- $\beta$-induced osteogenic differentiation of human mesenchymal stem cells in the TGF- $\beta$-activated MEK-dependent manner. Int J Mol Med 33: 534-542, 2014

19. Ray P and Chapman SC: Cytoskeletal reorganaization drives mesenchymal condensation and regulates downstream molecular signaling. PLoS One 10: e0134702, 2015.

20. Sengle G, Carlberg V, Tufa SF, Charbonneau NL, Smaldone S, Carlson EJ, Ramirez F, Keene DR and Sakai LY: Abnormal activation of BMP signaling causes myopathy in Fbn2 null mice. PLoS Genet 11: e1005340, 2015.

21. Kramman R and Humphreys BD: Kidney pericytes: Roles in regeneration and fibrosis. Semin Nephrol 34: 374-383, 2014

22. Touboul C, Vidal F, Pasquier J, Lis R and Rafii A: Role of mesenchymal cells in the natural history of ovarian cancer: A review. J Transl Med 12: 271, 2014.

23. Wise AF and Ricardo SD: Mesenchymal stem cells in kidney inflammation and repair. Nephrology (Carlton) 17: 1-10, 2012.

24. Okabe M, Ikawa M, Kominami K, Nakanishi $T$ and Nishimune Y: 'Green mice' as a source of ubiquitous green cells. FEBS Lett 407: 313-319, 1997.

25. Aomatsu E, Takahashi N, Sawada S, Okubo N, Hasegawa T, Taira M, Miura H, Ishisaki A and Chosa N: Novel SCRG1/BST1 axis regulates self-renewal, migration and osteogenic differentiation potential in mesenchymal stem cells. Sci Rep 4: 3652, 2014.

26. Livak KJ and Schmittgen TD: Analysis of relative gene expression data using real-time quantitative PCR and the 2(-Delta Delta C(T)) Method. Methods 25: 402-408, 2001

27. Gee CJ and Harris H: Tumorigenicity of cells transformed by Simian virus 40 and of hybrids between such cells and normal diploid cells. J Cell Sci 36: 223-240, 1979.

28. Howell N: Suppression of transformation and tumorigenicity in interspecies hybrids of human SV40-transformed and mouse 3T3 cell lines. Cytogenet Cell Genet 34: 215-229, 1982.

29. Kahn P, Topp WC and Shin S: Tumorigenicity of SV40-transformed human and monkey cells in immunodeficient mice. Virology 126: 348-360, 1983.

30. Nitta M, Katabuchi H, Ohtake H, Tashiro H, Yamaizumi M and Okamura H: Characterization and tumorigenicity of human ovarian surface epithelial cells immortalized by SV40 large T antigen. Gynecol Oncol 81: 10-17, 2001.

31. Kang MK and Park NH: Extension of cell life span using exogenous telomerase. Methods Mol Biol 371: 151-165, 2007.

32. Lee MK, Hande MP and Sabapathy K: Ectopic mTERT expression in mouse embryonic stem cells does not affect differentiation but confers resistance to differentiation- and stress-induced p53-dependent apoptosis. J Cell Sci 118: 819-829, 2005

33. Abraham S, Sweet T, Khalili K, Sawaya BE and Amini S: Evidence for activation of the TGF-betal promoter by C/EBP beta and its modulation by Smads. J Interferon Cytokine Res 29: 1-7, 2009.

34. Ramji DP and Foka P: CCAAT/enhancer-binding proteins: Structure, function and regulation. Biochem J 365: 561-575, 2002.

35. Zahnow CA: CCAAT/enhancer-binding protein beta: Its role in breast cancer and associations with receptor tyrosine kinases. Expert Rev Mol Med 11: e12, 2009

36. Lekstrom-Himes J and Xanthopoulos KG: Biological role of the CCAAT/enhancer-binding protein family of transcription factors. J Biol Chem 273: 28545-28548, 1998. 
37. Akira S, Isshiki H, Sugita T, Tanabe O, Kinoshita S, Nishio Y, Nakajima T, Hirano T and Kishimoto T: A nuclear factor for IL-6 expression (NF-IL6) is a member of a C/EBP family. EMBO J 9: 1897-1906, 1990.

38. Williams SC, Cantwell CA and Johnson PF: A family of C/EBP-related proteins capable of forming covalently linked leucine zipper dimers in vitro. Genes Dev 5: 1553-1567, 1991.

39. Katz S, Kowenz-Leutz E, Müller C, Meese K, Ness SA and Leutz A: The NF-M transcription factor is related to C/EBP beta and plays a role in signal transduction, differentiation and leukemogenesis of avian myelomonocytic cells. EMBO J 12: 1321-1332, 1993.

40. Haas SC, Huber R, Gutsch R, Kandemir JD, Cappello C, Krauter J, Duyster J, Ganser A and Brand K: ITD- and FL-induced FLT3 signal transduction leads to increased C/EBP beta-LIP expression and LIP/LAP ratio by different signalling modules. Br J Haematol 148: 777-790, 2010.

41. Gutsch R, Kandemir JD, Pietsch D, Cappello C, Meyer J, Simanowski K, Huber R and Brand K: CCAAT/enhancer-binding protein beta inhibits proliferation in monocytic cells by affecting the retinoblastoma protein/E2F/cyclin E pathway but is not directly required for macrophage morphology. J Biol Chem 286 22716-22729, 2011.

42. Nerlov C: The C/EBP family of transcription factors: A paradigm for interaction between gene expression and proliferation control Trends Cell Biol 17: 318-324, 2007.

43. Tsukada J, Yoshida Y, Kominato Y and Auron PE: The CCAAT/enhancer (C/EBP) family of basic-leucine zipper (bZIP) transcription factors is a multifaceted highly-regulated system for gene regulation. Cytokine 54: 6-19, 2011.

44. Pham TH, Langmann S, Schwarzfischer L, El Chartouni C, Lichtinger M, Klug M, Krause SW and Rehli M: CCAAT enhancer-binding protein beta regulates constitutive gene expression during late stages of monocyte to macrophage differentiation. J Biol Chem 282: 21924-21933, 2007.

45. Liu S, Croniger C, Arizmendi C, Harada-Shiba M, Ren J, Poli V, Hanson RW and Friedman JE: Hypoglycemia and impaired hepatic glucose production in mice with a deletion of the C/EBP beta gene. J Clin Invest 103: 207-213, 1999.

46. Croniger CM, Millward C, Yang J, Kawai Y, Arinze IJ, Liu S, Harada-Shiba M, Chakravarty K, Friedman JE, Poli V and Hanson RW: Mice with a deletion in the gene for CCAAT/enhancer-binding protein beta have an attenuated response to cAMP and impaired carbohydrate metabolism. J Biol Chem 276: 629-638, 2001.

47. Poli V: The role of $\mathrm{C} / \mathrm{EBP}$ isoforms in the control of inflammatory and native immunity functions. J Biol Chem 273: 29279-29282, 1998.

48. Zwergal A, Quirling M, Saugel B, Huth KC, Sydlik C, Poli V, Neumeier D, Ziegler-Heitbrock HW and Brand K: C/EBP beta blocks p 65 phosphorylation and thereby NF-kappa B-mediated transcription in TNF-tolerant cells. J Immunol 177: 665-672, 2006
49. Cappello C, Zwergal A, Kanclerski S, Haas SC, Kandemir JD, Huber R, Page $S$ and Brand K: C/EBP beta enhances NF-kappaB-associated signalling by reducing the level of IkappaB-alpha. Cell Signal 21: 1918-1924, 2009.

50. Liu Y, Nonnemacher MR and Wigdahl B: CCAAT/enhancer-binding proteins and the pathogenesis of retrovirus infection. Future Microbiol 4: 299-321, 2009.

51. Spooner CJ, Guo X, Johnson PF and Schwartz RC: Differential roles of $\mathrm{C} / \mathrm{EBP}$ beta regulatory domains in specifying MCP-1 and IL-6 transcription. Mol Immunol 44: 1384-1392, 2007.

52. Abraham M, Shapiro S, Karni A, Weiner HL and Miller A Gelatinases (MMP-2 and MMP-9) are preferentially expressed by Th1 vs. Th2 cells. J Neuroimmunol 163: 157-164, 2005.

53. Guo J, Zhang H, Xiao J, Wu J, Ye Y, Li Z, Zou Y and Li X: Monocyte chemotactic protein-1 promotes the myocardial homing of mesenchymal stem cells in dilated cardiomyopathy. Int J Mol Sci 14: 8164-8178, 2013.

54. Belema-Bedada F, Uchida S, Martire A, Kostin S and Braun T: Efficient homing of multipotent adult mesenchymal stem cells depends on FROUNT-mediated clustering of CCR2. Cell Stem Cell 2: 566-575, 2008.

55. Gerard C and Rollins BJ: Chemokines and disease. Nat Immunol 2: 108-115, 2001.

56. Rot A and von Andrian UH: Chemokines in innate and adaptive host defense: Basic chemokinese grammar for immune cells. Annu Rev Immunol 22: 891-928, 2004.

57. Dwyer RM, Potter-Beirne SM, Harrington KA, Lowery AJ, Hennessy E, Murphy JM, Barry FP, O'Brien T and Kerin MJ: Monocyte chemotactic protein-1 secreted by primary breast tumors stimulates migration of mesenchymal stem cells. Clin Cancer Res 13: 5020-5027, 2007.

58. Schenk S, Mal N, Finan A, Zhang M, Kiedrowski M, Popovic Z, McCarthy PM and Penn MS: Monocyte chemotactic protein-3 is a myocardial mesenchymal stem cell homing factor. Stem Cells 25: 245-251, 2007

59. Zhou YL, Zhang HF, Li XL, Di RM, Yao WM, Li DF, Feng JL, Huang J, Cao KJ and Fu M: Increased stromal-cell-derived factor 1 enhances the homing of bone marrow derived mesenchymal stem cells in dilated cardiomyopathy in rats. Chin Med J (Engl) 123: 3282-3287, 2010.

60. Zhuang Y, Chen X, Xu M, Zhang LY and Xiang F: Chemokine stromal cell-derived factor 1/CXCL12 increases homing of mesenchymal stem cells to injured myocardium and neovascularization following myocardial infarction. Chin Med J (Engl) 122 183-187, 2009.

61. Abbott JD, Huang Y, Liu D, Hickey R, Krause DS and Giordano FJ: Stromal cell-derived factor-1 alpha plays a critical role in stem cell recruitment to the heart after myocardial infarction but is not sufficient to induce homing in the absence of injury. Circulation 110: 3300-3305, 2004.

62. Mozid AM, Arnous S, Sammut EC and Mathur A: Stem cell therapy for heart diseases. Br Med Bull 98: 143-159, 2011. 